\title{
Economic Benefit Potential on Recovery of Solvent Lubricant Waste
}

\author{
Rinette Visca ${ }^{1}$, Mubarokah Nuriaini Dewi², Ade Julien ${ }^{3}$, Hera Dwi Paramita ${ }^{4}$, Ika Uswatun \\ Hasanah $^{5}$ \\ \{rinette.visca@yahoo.com¹,mubidewi88@gmail.com², ade_julien12@yahoo.com³, \\ heradwiparamita57@gmail.com ${ }^{4}$, ikauswatunhasanah@gmail.com $\left.{ }^{5}\right\}$ \\ Chemical Engineering- Jayabaya University $1,2,3,4,5$
}

\begin{abstract}
Solvent Lubricant Waste Production of an XYZ oil company was very high, this is due to the many laboratory tests that require organic solvents for washing lubricant of equipment. In addition, laboratory requirements for organic solvents are also very high, to overcome this problem, the distillation of organic solvents was carried out to obtain organic solvents of lubricant waste that can be recovered. The purpose of this study was to regenerate the solvent of solvent lubricant waste. The purity of organic solvents from the resulting distillate was analyzed by using the Fourier Transform Infrared (FTIR) Spectroscopy. Results showed that the recovery of solvent lubricant waste is financially beneficial for the company. With an onsite solvent distillation unit will reduce solvent/consumables purchase order costs by $90-95 \%$.
\end{abstract}

Keywords: Recovery, Solvent, Lubricant waste, FTIR, cost-benefit analysis

\section{Introduction}

The lubricant has been used primarily for reducing friction between moving parts of various machinery or equipment, minimize material wear, improve the efficiency of equipment and for energy savings. This large amount of waste lubricant has a significant impact on both economic and environmental aspects. Researchers are concerned about environmental problem arises of lubricant waste. Lubricant waste may harmful to the environment when burnt as a low-grade fuel or into water streams including sewers. This may result in groundwater and soil contamination.

Lubricant waste has a significant impact on the environment. The regulation in Indonesia stated that lubrication waste must be recycled through the third party as hazardous waste treatment. With ever-growing global environmental awareness, even developing and most of the underdeveloped countries have statutory regulations guiding the treatment of hazardous residual wastes generated through waste treatment.

The need for the organic solvent of XYZ oil company is very high. The organic solvent in this laboratory was effective for dissolving impurities by washing machinery equipment and also for viscosity testing of used lubricant as hazardous waste. Since lubricant is non-polar, solvents which is suitable for cleaning equipment when contact with a lubricant are organic solvents. Organic solvents are solvents that generally contain carbon atoms in their molecules and they are lipophilic. 
One of the organic solvents is toluene. Toluene, also known as methylbenzene or phenylmethane, is a colourless clear liquid that is insoluble in water with a paint thinner and smells like benzene. It is an aromatic hydrocarbon that is widely used in industrial feedstocks. Toluene has the molecular formula $\mathrm{C}_{6} \mathrm{H}_{5} \mathrm{CH}_{3}$. Its boiling point is $110,6^{\circ} \mathrm{C}$. This study was using technical grade toluene and toluene pro analysis (toluene p.a).

A number of studies to remove various impurities in used lubricating oil and to reuse solvents as valuable products have been attempted, such as; acid-clay [1], hydrogenation [2], distillation [3], and solvent extraction [4]-[6]. Although each method has advantages and disadvantages, distillation has displayed higher efficiency in solvent recovery. This method is environmentally safer than the others, more beneficial due to its low operational costs as well.

The purpose of this study was to evaluate economic benefit after solvent regeneration from used lubricant oil. Being processed through fractional distillation that separates the pure solvent from contaminants. Solvent recovery is designed to help reduce liquid waste disposal expense thus, providing economic benefit. Recycling of solvent lubricant waste will be beneficial in reducing solvent cost.

\section{Experimental Section}

\section{A. Materials}

Technical grade Toluene, Toluene pro analysis (toluene p.a), Karl Fischer titrator (mixture of iodine-sulfur dioxide-pyridine in methanol solution), FTIR Fourier Transform Infra-Red (FTIR) Spectroscopy, Solvent lubricant waste which contain Technical Grade Toluene, solvent lubricant waste which contain Toluene p.a., atmospheric distillation equipment, were supplied by Laboratory Product Development Lubricants XYZ company.

\section{B. Methods}

This study beginner with the problem identification through heritage studies from various literature, and existing information from an XYZ oil company. Research then proceed with a laboratory experiment. Toluene as the organic solvent is recovered from Solvent lubricant waste which contains Technical Grade Toluene and toluene p.a using an atmospheric distillation setup (Figure 1). The base oil and $500 \mathrm{ml}$ solvent lubricant waste were heated with an electric mantle to a temperature of $120^{\circ} \mathrm{C}$. It was higher than the toluene boiling point $\left(110,6^{\circ} \mathrm{C}\right)$ so as to ensure the total removal of the solvent from the solvent lubricant waste. The purity of organic solvents from the resulting distillate was analyzed by using the Fourier Transform Infra-Red (FTIR) Spectroscopy. Data on costs are analyzed and conclusions are drawn from the results of the analysis.
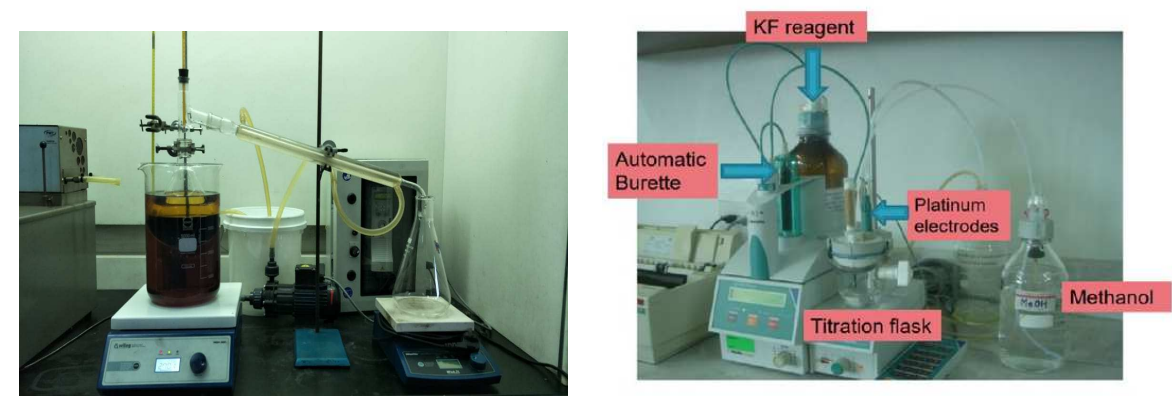

Figure 1. Atmospheric distillation of solvent lubricant waste (left) and Karl Fischer Equipment (right) 


\section{Results \& Discussions}

The organic solvent in this laboratory was effective for dissolving impurities by washing machinery/ equipment and also for viscosity testing of used lubricant as hazardous waste. Method for viscosity testing is capillary pipe flushing, by using solvent toluene p.a and technical grade toluene. The following table showed distillate produced and moisture content.

Table 1. Volume of Distillate

\begin{tabular}{llll}
\hline Sample & Type of Waste & Distillate volume $(\mathrm{ml})$ & Moisture $(\mathrm{ppm})$ \\
\hline A & $\begin{array}{l}\text { Solvent Lubricant Waste which contains } \\
\text { Technical Grade Toluene }\end{array}$ & 142 & 220 \\
B & $\begin{array}{l}\text { Solvent Lubricant Waste which contains } \\
\text { Toluene p.a }\end{array}$ & 145 & 228 \\
\hline
\end{tabular}

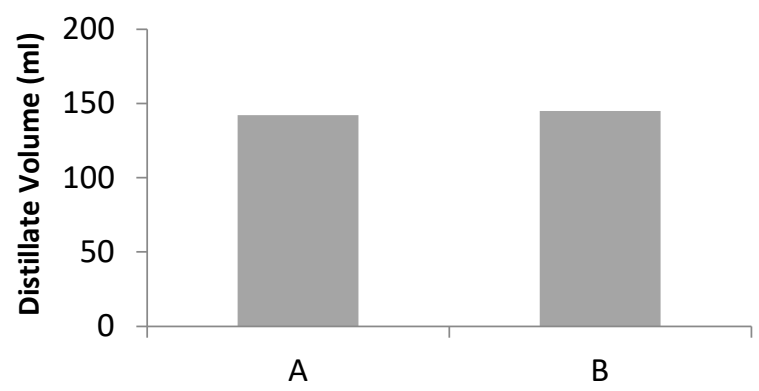

Figure 2. Recovered solvent volume after distillation process

As the results, distillation produced was almost similar to $142 \mathrm{ml}$ of Technical Grade Toluene and $145 \mathrm{ml}$ of Toluene p.a from solvent waste (Figure 2). The presence of water in solvent lubricant waste due to viscosity testing of lubricants by the Karl Fischer method, and the result was $220 \mathrm{ppm}$ and $228 \mathrm{ppm}$.

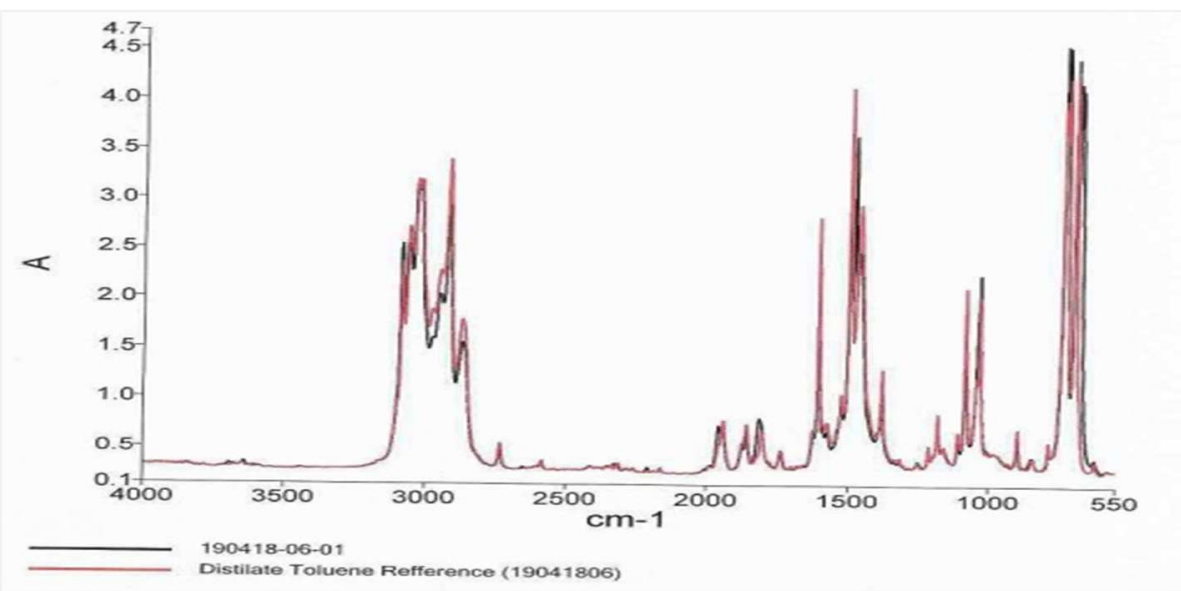

Figure 3. Peaks of Solvent Lubricant Waste with Distillate Toluene Reference 
third party and transportation (\$125.71 and \$34.25). Procurement for distillation set was $\$ 250$ per unit. Annual electricity consumption depends on time using the distillation unit over the recycled solvent waste volume. It was $\$ 51$ for technical grade Toluene and $\$ 25.49$ for toluene $\mathrm{p}$ a annual electricity consumption. Annual saving with recycling for technical grade Toluene is \$1293.4a and for technical grade Toluene and \$2243.91. From the observation, using distillation to obtain high purity recycled solvents is recommended. With the rise of the green economy, solvent recovery has become the research hot all over the world, particularly the recycle for use oil has the tendency of high technology and large scale [8].

\section{Conclusion}

Solvent waste recovery not only saves the cost of purchasing new solvents but also ecofriendly. Recycling helps the environment with the impacts of hazardous chemicals to protect it from water pollution. Solvent disposal to the third party requires a huge cost. The pure solvent is recovered through a simple solvent distillation process that separates the clean solvent from impurities or any harmful substances. A good solvent recovery system may purify the solvent of solvent lubrication waste, after a simple recycling application. The recovered solvent contains high purity so it is proper to be reused in the viscosity testing process again. With an onsite solvent distillation unit will reduce solvent/consumables purchase order costs by $90-95 \%$. The recovery of the organic solvent is financially beneficial for the company due to its low operational costs.

\section{References}

[1] S. Eldeen F. Hegazi, "Recycling of Waste Engine Oils Using Different Acids as Washing Agents," Int. J. Oil, Gas Coal Eng., 2017.

[2] UNEP, Basel Convention: Technical Guidelines on Used Oil Re-Refining of Other Re-Uses of Previously Used Oil. United Nation Environment Program Basel Convention Series/SBC no. 02/05., 2002.

[3] N. Mahale, P. P. Kulkarni, Y. Mahajan, S. B. Attard, and S. Ingle, Recovery of Hydraulic Lubricant Oil by Solvent Distillation Process from Industrial Waste. 2012.

[4] H. a L. I. Durrani, M. I. Panhwar, and R. A. Kazi, "Re-Refining of Waste Lubricating Oil by Solvent Extraction,” Mehran Univ. Res. J. Eng. Technol., 2011.

[5] M. O. Aremu, D. O. Araromi, and O. O. Gbolahan, "Regeneration of used lubricating engine oil by the solvent extraction process," Int. J. Energy Environ. Res., vol. 3, no. 1, pp. 1-12, 2015.

[6] V. Katiyar and S. Husain, "Used lubricating oils recycling using solvent extraction," Current World Environment, vol. 5, no. 1. 2010.

[7] D. A. Camiener, "How Much Does Use a Solvent Distillation Unit in Your Lab Cost?," $C B G$ Biotech Blog, 2018.

[8] M. Yu, H. Ma, and Q. Wang, "Research and recycling advancement of used oil in China and all over the World," in Procedia Environmental Sciences, 2016, pp. 239-243. 